\title{
Patients with Dementia and Epilepsy: Does Family and Kinship Care Matters?
}

\author{
Ravinder Singh ${ }^{1}$, Vibha Sharma ${ }^{2}$, Upmesh Kumar Talwar ${ }^{3}$ \\ ${ }^{1}$ Department of Medical Anthropology, Institute of Human Behavior and Allied Sciences (IHBAS) Hospital, \\ Faculty of Medical Sciences, University of Delhi, GNCT Delhi \\ Delhi, India \\ ${ }^{2}$ Department of Clinical Psychology, Institute of Human Behavior and Allied Sciences (IHBAS), \\ Government of NCT Delhi, Delhi, India \\ ${ }^{3}$ Department of Social Work, Central University of Himachal Pradesh, Dhramshala, India \\ Email: medicalanthropology@hotmail.com,vibhakabir@rediffmail.com, talwarmsw@gmail.com
}

Received January $18^{\text {th }}$, 2013; revised February $26^{\text {th }}, 2013$; accepted March $5^{\text {th }}, 2013$

Copyright (c) 2013 Ravinder Singh et al. This is an open access article distributed under the Creative Commons Attribution License, which permits unrestricted use, distribution, and reproduction in any medium, provided the original work is properly cited.

Paper reports nine Case Studies each of epilepsy and dementia patients. Content analysis of family and kinship care in their families reveals significant issues of social stigma, marriage, school education, employment etc. among epilepsy patients as main concern while care of dementia patients in family concerns to spouse caring. It explores stigma affecting socio-cultural understanding of epilepsy and dementia. How these patients are cared within their family. Who care them most? It illuminates relevance of family and kinship care givers and recommend culturally appropriate interventions in community of such neuropsychiatric diseases.

Keywords: Epilepsy; Dementia; Family and Kinship Care

\section{Introduction}

Anthropology of caring has already explored a new path for individuality, alterity, gender relations, and new form of sociality in everyday life experiences of caregivers, spouses, children, and other relatives who provides day to day care to person with illnesses living in the home (Saillant \& Genset, 2007). Normally caring is considered to be the work of the women followed by other kinsmen in the family. Can the family and kinship caring intervention be analyzed in home or in community or in hospital situation? Anthropologists have reformulated the kinship as the study of form of caring and being cared for (Borneman, 1997). We illuminate family and kinship care, as complementary part of comprehensive patient care, in the families of patients with dementia and epilepsy in the paper.

We explore care and its burden in the family of these patients. Here we are giving the brief about dementia and epilepsy followed by case studies of patients focused on the family and kinship care composition and their sibs involved in the caring. Clinicians give the prime importance to clinical symptoms, presentations and management of neuropsychiatric diseases but management of these diseases requires comprehensive care within the families of such patients besides medicines.

\section{Dementia and Epilepsy}

The dementia and epilepsy are neuropsychiatric diseases and are causing social suffering to the family as well as to community. About 450 million people are affected in the world. One estimate reveals 13 percent of disability-adjusted life years (DALYs) are due to neuropsychiatric disorders (Chandra et al., 2006). Dementia/Alzheimer's disease (AD) is a deterioration of intellectual function and other cognitive skills interfering with social and other occupational functions. It is most common diseases worldwide among the people above 65 years (Ibid). The prevalence of dementia becomes the double with every five year of increase in age (Henderson \& Jorm, 2000; Chandra et al., 1998; Hendrie et al., 1995; Rajkumar, Kumar, \& Thara, 1997; Jorm \& Jolley, 1998). The behavioral and other psychological symptoms of dementia are a major source of stress to family members caring their patients. It has been proved that training to family caregivers in behavioral management techniques, including problem solving, memory training, and reality orientation has reduce the level of agitation and anxiety in patients with dementia (Brodaty \& Gresham, 1989; Haupt, Karger, \& Janner, 2000), counseling interventions for caregivers have shown positive results in such cases(Marriott et al., 2000). Medical anthropologists have produced remarkable work on dementia/Alzheimer's Disease in different national sites of Brazil, Canada, Germany, India, Japan, Netherlands and the United States around the world (Leibing \& Cohn, 2006; Cohn, 1994, 1998, 2003). It includes dementia-near-death and Life itself (Kaufman, 2006), physician and family perspective on "troublesome" behavior of people with dementia (Hinton et al., 2006), diagnosing dementia (Graham, 2006); genetic susceptibility and Alzheimer's disease (Lock, Llyod, \& Prest, 2006); and social, cultural and ethical issues relating to patients with dementia (Singh et al., 2011). Lawrence Cohn's No Aging in India: Alzhemier's, the Bad Family, and Other Modern Things, is the pioneer anthropological work on dementia in India (Cohn, 1998). 
Epilepsy or Seizure disorder is cerebral malfunctioning, a pattern of repeated sudden brief attacks of altered consciousness, motor activity or sensory phenomena. Studies have been reported on the epilepsy covering the different aspects and about 10 million people are suffering from epilepsy in our country (Gourie Devi et al., 2004a, 2004b). An estimate based on projected people with epilepsy is 5,500,000 and 4,100,000 of them stay in rural areas. There is a significant level of underreporting of such cases because of the stigma associated with seizures. The ethical and legal issues related to patients with dementia and epilepsy (Sharma et al., 2011), childhood epilepsy and knowledge, attitude and perception of the school teachers of Delhi (Khurana et al., 2012) have been critically examined in Indian perspective. Studies on caring epilepsy patients have also illuminated spiritual psychotherapy of caregivers (Singh et al., 2012a) and care giver burden, personality characteristics and coping strategies of care givers of patients with epilepsy (Singh et al., 2012b). A well known psychiatrist and medical anthropologist has very nicely documented all these aspects as the social course of epilepsy suffering, chronic illness as social experiences in his field work in China (Kleinman,1995).

\section{Material and Methods}

Interview of the Dementia care giver and Epilepsy patients' as well as of their care givers were conducted between August 2006 and July 2007. Detail of socio-demographic variables of sixty patients, dementia (22) and epilepsy (38), is given in Table 1. A semi-structured schedule was used for interview during their neurology OPD visit as well as through home visits to substantiate the desired information at the week end. Initially

Table 1.

Socio-demographic variable of dementia and epilepsy patients.

\begin{tabular}{|c|c|c|c|c|}
\hline S.No. & \multicolumn{2}{|c|}{$\begin{array}{c}\text { Socio-demographic } \\
\text { Variable } \\
\end{array}$} & $\begin{array}{c}\text { Dementia } \\
\%(\mathrm{~N}=22)\end{array}$ & $\begin{array}{c}\text { Epilepsy } \\
\%(\mathrm{~N}=38)\end{array}$ \\
\hline 1. & Age & $\begin{array}{c}\text { in } \\
\text { Mean Range }\end{array}$ & 63.5 & 36.7 \\
\hline \multirow{2}{*}{2.} & \multirow{2}{*}{ Sex } & Male & $10(16.66)$ & $22(36.66)$ \\
\hline & & Female & $12(20)$ & $16(26.66)$ \\
\hline \multirow{2}{*}{3.} & \multirow{2}{*}{$\begin{array}{l}\text { Marital } \\
\text { Status }\end{array}$} & Married & $22(36.66)$ & $15(25)$ \\
\hline & & Unmarried & 01 (16.66) & 13 (21.66) \\
\hline \multirow{2}{*}{4.} & \multirow{2}{*}{$\begin{array}{l}\text { Financial } \\
\text { Support }\end{array}$} & Yes & 21 (35) & 11 (18.33) \\
\hline & & No & $01(1.66)$ & 17 (28.33) \\
\hline \multirow{2}{*}{5.} & \multirow{2}{*}{ Religion } & Hindu & 22 (36.66) & 21 (35) \\
\hline & & Muslim & 00 & 17 (28.33) \\
\hline \multirow{3}{*}{6.} & \multirow{3}{*}{ Education } & $\begin{array}{l}\text { Below } \\
\text { Primary }\end{array}$ & 02 (3.33) & $12(20)$ \\
\hline & & Secondary & 11 (18.33) & 17 (28.33) \\
\hline & & $\begin{array}{c}\text { Above } \\
\text { Secondary }\end{array}$ & $10(16.66)$ & 09 (15) \\
\hline \multirow{3}{*}{7.} & \multirow{3}{*}{$\begin{array}{c}\text { State } \\
\text { Domicile }\end{array}$} & Haryana & 01 (1.66) & 00 \\
\hline & & Delhi & $13(21.66)$ & 22 (36.66) \\
\hline & & Uttar Pradesh & 08 (13.33) & $16(26.66)$ \\
\hline
\end{tabular}

one of us (RS) visited some of them purposely to complete the information which they could not share about traditional healing practices, if they consulted? Most of them don't like to share with the physicians in their consultation rooms who, as they think, exclusively meant for diagnosis, prescription and pay less attention to these aspects of alternative healing consultations.

While the interviews, with the consent, of the care giver of dementia patients were held in the wards as well as in OPD of the hospital. Someone from the family members or other kinsmen always accompanied the patients with dementia and was interviewed as a care giver.

\section{Patients with Dementia and Epilepsy}

Patients with dementia which were interviewed from the different places in Delhi like Sundar nagari, Gokulpuri, Pandav nagar, Dilshad garden, Krishna nagar, Nehru Nagar, Shahdara, New Govindpura, all comprised as Trans Yamuna of Delhi. Most of patients come to this tertiary care neuropsychiatric hospital. A semi structured schedule was divided into four major sections: first, deals with the socio-demographic detail; second, food habits-how many times patients in the past has been taking the meal per day, constituents of the staple diet-green vegetables, fruits consumption, spices consummation, Non/vegetarian. Third, Family profile, family supporting members, time spent in caring and the fourth, life history of the person: scholastic performance, nature of job and earning, number of hours spent in the jobs, level of satisfaction and stress of the job. Life after the retirement, marital history, family responsibilities, peer group activities in the life and important events in the life. This information was collected in a structured schedule. One of us (RS) conducted an unstructured interview with care giver. Here while writing this paper we have restricted our interpretation to the family and kinship care composition and how much time they give in the care of patient with dementia. Other detail neither analyzed nor utilized, as it was useful for the clinical and neurological interpretation.

Whereas most of the epilepsy patients were from Uttar Pradesh followed by the Delhi which share similar culture, but religious practices varies according to their religion viz. Hindu and Muslim. A large number of epilepsy patients come from Aligrah, Gaziabad, Muzffarnagar, Meerut, Bulandshar, Moradabad, Gujrola, where as some of these people are from transyamuna areas of Delhi which includes Nanad Nagari, Sunadr Nagari, Wazirabad, Yamuna vihar, Gokulpuri, Saboli extension, Ashok Nagar, including other parts of Delhi. In some cases people came from other far of places- nearby districts of Haryana for the treatment to this tertiary care hospital. In our patients population most of them are from the low socioeconomic group and are living in the nuclear families in Delhi whereas the people from the Uttar Pradesh belong to rural families are engaged in agriculture activities.

\section{Patients with Dementia}

We are giving nine brief case histories of patients with dementia-four women and five men. Most of the details, such as diet, routine of patient in the past years, brain activities of calculation, teaching etc. help to Neurologist in clinical assessment of these patients and deliberately have not used. We have restricted family and kinship care involved in dementia patients 
(patients name are pseudo name).

\section{Women with Dementia}

1) $H K D, 60$-year-old Hindu jat woman, came from the rural village Rehman Pur of Shamali, Bulandshar, UP. She is illiterate housewife and look after the agriculture activities in the house as well as in the field in past. She had been working 12 to 17 hours every day. She had seven children, four boys and three girls. All are married and well settled. Married sons have settled away from their ancestral village. Both, husband and wife, $\mathrm{HKD}$, stay back alone and their monthly income is about $10,000 /-p m$. She had been diagnosed a case of AD at the age of 60 years. She is well build and tall. A brief history about her life style in past shows that she is married for 45 years where in she took all the responsibility of the household activity. Her husband told about her she never felt more stress. She spent 3 to $4 \mathrm{hrs}$ in recreational work with her peer group. Her husband claims that she is satisfied. Nothing has disturbed her in her family.

In the Family and its support, all sons stay away from the parents, particularly from the patient mother, husband visiting their married sons and daughter. Wife, HKD, remains back in her house. Often sons contribute economically to the parents. But physically they hardly stay long. It is apparent parents living alone in the village setting. Most of the time husband cares his wife; none of the daughters-in-law stay together though their children often stay back with grandmother. Financially sons support the parental family. Married life of the patients, $\mathrm{HKD}$, is very satisfactory and supportive to each other in their life for 45 years. As the mother, HKD cared well her children, home and enjoyed happy married life in company of husband.

2) $K R$ is another woman, above 60 years, diagnosed with Dementia. She had been complaining the memory loss, failing to recognize the sibs and kins in the family during the early November and December 2006. Her family members treated her with local trained doctors in Baraut. But there was no cure till Jan. 2007. Meanwhile she rapidly lost the memory and referred here where she was diagnosed as dementia of AD type.

Her daughter brought her in Delhi for treatment. This daughter further adds that KR has four children and a husband. One sister and son are already married. Married son had been living together till October, 2006, just before these symptoms of memory loss appeared in KR. KR used to love her married elder son Ashok and his children and till then KR was very active in the home chore activities of the house. As the patient began to exhibits the symptoms as mentioned earlier, she now requires more time for her care and sympathy of other family members. During this time, elder married son, refused to take care of her mother and his wife also refused to look after her mother-in-law. Her husband also refused to care her in such a situation and even did not help for her treatment as the wife. Then her unmarried two sons in the state of dilemma transferred her to their elder sister's house in Delhi for care and treatment. Both unmarried sons are looking after the economic expenditures of patients - their mother. In sum, married daughter is looking after her $\mathrm{AD}$ mother belongs to the high socio economic stratum of a rural village where a married daughter ideally does not keep her parents in her in-laws house. Two unmarried sons supporting the economic needs, but still seek the other social support from their married sister.
3) SK, 71 years old Hindu woman, housewife, had three children-one son and two married and one married son is living on the top floor of the three story house. SK and her husband live on the ground floor. Her only married son has two children living separately on top of the house. Her husband adds further that he runs his family life on the pension of Rs 3000/-pm and his son hardly supports them, in contrast they support as their son's family. Their son does not earn much.

4) $A D, 75$ years, old Hindu illiterate woman has five married children and the husband who look after her for the four years. Four years ago she developed the dementia and lost to no work. $\mathrm{AD}$ remains the part of family and being cared by the well settled married five sons and a daughter. Her daughters-in-law and their children care much. She had been a active housewife an used to work 8 to $10 \mathrm{hrs}$. She takes the different smoking means, traditional hukka, chilim, tobacco and bidi. She does not earn herself. As far as her part on the responsibility of bring up children which did nicely and had their own house, settled well all children and still pay attention to the social responsibility. Occasionally she spends times with her pear group. As her younger son tells that she thinks much of the past unpleasant incidences.

\section{Men with Dementia}

5) $B S$ is illiterate agriculturist Hindu Khastryia from Gorakhpur district in eastern UP and diagnosed for the vascular dementia. He had more than 40 years of married life and blessed with five children: two daughter and three sons. His wife supports in his endeavors and children occasionally help him and are settled in Delhi. Patient is second among his sibs and he cared all younger sibs himself. He expressed that he did not did much for his own children. Where as his younger brothers hardly cares him now it is this hurts and make him sometimes sad.

He belongs to extended family of 10 to 11 family members. His wife cares him very well. His two sons work, elder works as auto driver in Delhi and both remain away from their ancestral residence where their parent stays alone. The wife is main the care giver. Children are away from the caring work of their father. Though BS is brought to Delhi for the treatment and hardly gets any support of care from other secondary kinsmenparticularly his younger married brothers and their children. Though, BS took all the responsibility of paternal family and made house for them, settled them, and also met social obligation.

6) SC, 65 years, dementia patient, a post graduate from Govindpura of Trans Yanmuna Area suffering with dementia. He is retired from the active service of 33 years as account Officer and getting a pension of Rs 6000/pm as tells his wife.

In Family care all are living in the joint family of the SC which is comprised of two married son and their three and two children respectively. Their two younger sisters are married away. Families of both son stay with SC and both run the electricity goods shop. Wife of SC is main care giver. House of SC is three storied. Eldest son and his family stay on the top floor, younger son and his family stays on the first floor and SC with his wife stay on the ground floor. Two married sons staying with SC on two different floors-layered structured houses where their bonds are weak with their old parents. Both sons hardly interact in the day and they are busy in their personal families after the hectic day at the shops. Wife of SC further adds that 
some unpleasant issues are discussed in his presence which hurt him more. Such incidents make SC to think about some jobs or to earn money for which is they are looking towards the married sons. However he has retired from the government office where he performed the mental calculation and kept himself active in life. He tried some pity shop in the house but still it is his wife who runs it now, as does not enjoy any more this work. Prior to it he tried another shop, halwai ki duhkan, but he gave up after sometime. SC tried in many engagements to earn money after the retirement but failed. His wife looks after for his care. As far as daughter-in-laws are concern they hardly care him. Reasons are very different in this case as wife tells, he is not able to maintain his normal body dressing and often he forgets to wear undergarments which put other care givers away in the family, particularly the daughter-in-laws and their children or even their own sons hardly pay attention the personal care of their father. It left to the wife alone.

7) FS, 58-year-old man, is matriculate and has retired as subPost master from the government services after serving for the more than 20 years and living in his own house. He depends on the pension. He had been diagnosed for Alzheimer Disease (AD) in 2004 being treated since then. He is married for more than 40 years and had three sons. Elder one is married and separated from the parental home and living separately with his wife and two children. FS and his wife stay on the top floor and FS is not aware about separation of his elder son form his family. As far as care of FS concern it is his wife who most of the time on the caring her husband, FS, who is supported their two unmarried sons. Though, they could not give much time for care to his father as they are busy in jobs and though stay with the parents. As wife tells further that FS cannot manage his normal behavior and is cool and calm but needs the direction for the self management. Often he stares women, young girls and put off his garments, particularly the lower one. Such frequent episode forced his wife in embarrassing situation, to keep him separate from other family members. Their monthly pension is about 9000/-pm. FS expects much attention from his eldest married son who is living separately with his two children.

8) SS, 70-year-old Hindu causal agricultural labor from a rural village in Muzzafarnagar, UP. He is illiterate and unmarried among six married brother and sister. All are well settled and living in joint family. He is being looked after by the elder brother and his wife and their children. His other brothers also pay attention to him. In his life he has seen many ups and down. He has huge amount of debit and sold off a piece of his agricultural land and tried several menial works which had caused much suffering and put him in depression. Prior to onset of the $\mathrm{AD}$ dementia he used to earn at least Rs 1500/-pm. But he now is dependant up on the brothers and their family adds one of his younger brothers. He is looking after the children of his brother and younger sisters. Sometimes SS is not able speak much. Previously he used to meet relatives at different places.

9) IJS, 66 yrs, an old Sikh male, suffering from the dementia, staying with his wife, with a married son and two grand children. His wife care and manages to her husband (IJS). IJS used to earn Rs 2000/-pm from his factory. He had been trained as fitter and had set up his own factory where he used to work for 15 to 20 hrs per day. He was very satisfied form his job. They live in their own house. Wife cared well IJS as they are living together. Daughter is already married away and do not support much. IJS used to run a factory and supervise the fellow work- ers. Gradually he forgets things and subsequently fails to recognize his workers in the factory and fail to do minor calculation. Still he is on the treatment. He often goes to his factory with the son and tries to do trivial thing under supervision.

\section{Patients with Epilepsy}

We summarize here the brief case histories of Patients with Epilepsy: five school children, three married women and a married man (name has been changed).

\section{School Children with Epilepsy}

1) $V K, 16$ years, another school child of $12^{\text {th }}$ class preparing the board examination. His mother narrates about his seizure began when he was eight years old. Toady nearly eight years passed in the treatment for the seizure. During past eight years, some traditional healers treated him for one year in his maternal uncle house in Himanchal Pradesh. These healers used, as his mother narrates further, tabeej, mantra rituals and scared thread etc. but VK had no cure in his maternal uncle house. He visited the different places for the traditional treatment including the well known big hospital in Delhi. Initially, as his mother tells that she did not know it is a disease, while one doctor treating him then told her that it is a disease, epilepsy, and doctor referred him to this hospital and VK re-assumed the treatment in the tertiary care neuropsychiatric center. Further she adds about VK that he feel shyness or hesitates in visiting to the hospital after an interval of fifteen days. His mother admits the trouble in bringing him here in outpatient department for the routine checkup. He does not want to come very frequently, she continues further that his friends and neighbor make fun of him by saying that his treatment is going on from this hospital, and feels it. As his mother says

\section{"Main usko chupake lati hun taki padosi bhi nahi jante ke eska ellaz yahan se ho raha he aur VK ko ye achha nahi lagta ki usko bar bar yaha ana achacha nahi lagta he!” (I bring him hospital in the hiding, he does not like to visit the hospital frequently, even his friends and our neighbor do not know about the treatment. It is only we the family know the about it and we do not share his treatment with other).}

However his treatment continues from the hospital. His seizures are under controlled.

2) $K V, 13$-year-old boy, study in primary class in his home town Moradabad, having the complaints of seizures since 2007 and on 27 May 2007 he had 9 episodes of seizures and followed by 3 seizure on the next day. Because of the complaints neither he was not allowed to appear in the examination nor he appeared and finally he dropped a year in the fifth class. KV stays with his uncle in Moradabad and his father work in Gajrola where he is Patwari visit him at the weekend and could not pay attention to his academic activity. In the class situation has classmates tease him due to Caste Status and often pass the derogatory remarks due to his caste and it creates tension and always haunt him. He requested his father to change school due to this. KV feels disturbed in home could not concentrate on the studies. Common shouting or asking with hard word to get thing done caused ultimately seizures (?). This patient was referred on the advice of the some relative to this hospital.

3) SNZ, 12-year-old girl from the Muslim lower socioeco- 
nomic status from the Tahirpur village near to our hospital, she has been diagnosed for the seizure for the five years. She had first episode of the seizure at the age of seven years, in the school and it continues to the next few days. As first episode of the seizure her took her to the local healer of their community, Molvie, and for the 6 months she remains under his treatment but her parents visited again another healer, Ojha but nothing cured her illness, and her father visited in the hopeless situation to Pediatrician, who advised her father for the proper neurological treatment and referred to our hospital. She had reduced the frequency after the treatment much from every day to week, then in ten days to once in a month within a year and her seizures was under the control. Her school teacher advised her not to attend the school and parents though continue her treatment. She lost the precious years of school education due to this disease.

4) $S N D, 18$ years male, a $9^{\text {th }}$ class student in the Aligrah has been suffering the seizure disorders for the past three years and discontinued his studies because of seizure and though he used to cycle $6 \mathrm{~km}$ one way to go to school. He had first episode of seizure at the age of 15 years and his family members took the treatment form the local healers in Chachera, Aligrah, UP. He also went to Vaid Rajvir Singh who is also well known as Bhagatji who had claimed the cure of several cases of the epilepsy. Snd was given the treatment for the one year and it forced his studies and the vaid treatment gave no relief to him. Though the cost of herbal medicinal treatment was Rs 42/-per month. He was also treated by Traditional healers' for epilepsy. While he was being examined for the diagnosis in the OPD then his father planned for another visit in Anupshare near Blundshar. But a neighbor, who had been taking the treatment from the hospital, the advice his father, had advice to visit this hospital for the treatment. His treatment continues now from the hospital but still his family members are looking for the alternative healing. Snd wants to continue his studies but his parents prevented him due to fear and social stigma felt in school as well as in neighborhood areas of to his house. It seems that family feel the stigma in the society.

5) USH, 16-year-old girl from Nand Nagari, Delhi. She is the student of $8^{\text {th }}$ class and recently complaining the seizures for four years. She continued the treatment straight from this hospital. Her seizures subsequently controlled. Seldom episode of mild episode of seizure disturbed her and these may occur in the school. Here she expresses that their teachers and class mates help at the time of the seizures. She felt that both teachers and other students are helping her at the time need. She suffers and she says

"Kash mai mar jaun, bahut ho gaya es bimari se, har samay dar laga rahta he" (If I could die, it is enough of seizures. Every time I am afraid of seizures)

She further released the economic strain of expenditures on this disease made her sicker as she says

"bahut paise kharch ho gaye, lekin kuch tik nahin hota, acha hota ki mai mar jaun! Na tik se pad sakete he, Na khel sakete he!" (Much has been spent on this disease; nothing turns right to my disease. It would be better if I die. Neither I cannot study well nor can play well)

Ush has developed a guilt which is giving her more suffering than the disease.

\section{Married Women: A Hidden or Unheard Voice!}

6) Two Sisters, Arth (19) and Svit (17), identified for the seizures disorders. There are three sisters; all suffer of seizure disorders, among four children of poor parents from Hathas in Aligrah, UP. About two years before this visit, as her mother informs that the elder two sisters were under the treatment of local healers. As she narrates further the episodic drama and the treatment procedures of healers: pir, mulaji, tantrik, etc. in Hathras. A Mulaji, a Muslim religious healer, treated these sisters in Gahaziabad who administered some herbal medicine and massaged the Sunflower oil on the whole body of both and it continues for the nearly two months. Their mother noticed no relief from the local treatment. She was totally lost to hope. A closed relative told about these symptoms as epilepsy and direct for the treatment. This relative stay in Delhi and is well educated in the often interact the family. These two married sisters were referred and presented themselves in the OPD and treatment follows.

Meanwhile elder sister Arth was married off in the state of hopelessness of epilepsy cure and Svit visits the hospital with her mother for the treatment and Arth also come along when she need medicine. Arth never come with her husband and she try to make her way out to the hospital. On the each visit 15 days medicine are given to her and hence it seems she visits her mother every two weeks and stay till she gets her medicine. Her mother informs that it was told in advance to her husband and his parents' i.e. in-laws. But it seems not so (?). As she continues to narrates episode of seizure during the marriage of Arth, her elder daughter marriage she narrates while Arth was about to take the phere-in Hindu ritual of marriage both husband and wife take seven scared rounds of fire in presence of the all the relatives, then patient had an attack of seizure in the special room and the phere were delayed for one hour then it was managed to carry out the phere with much of the defense to the groom relatives.

Their mother while narrating the suffering caused due to the disease she expressed her agony

"Ya to bhagwan mujhe uthale, ya mere tino batiyo ko tik kar de!" harma jeevan nark ban gaya he!"(Let the God give me the Death or Give the cure of all my three daughters, our life has become the hell!).

She became sad and tells there is nothing enjoying in my life and she broke up to weep.

7) Yasda, 26 years, married woman from Nand Nagari who is suffering seizure disorder for past thirteen year. As her care giver, husband, accompanied to OPD. She had injuries on the forehead near left eye. She had been treated for it in GTB Hospital first in emergency after she was referred to here with her husband. one of us (RS) saw her feeling uneasy and dizziness and relaxing the on the chairs near to Clinical examination room and I offered her and my room where she relaxed on the stature and her Husband and her Parents sat outside the room and one of us (RS) conducted informal interviews of her parents.

They narrate that Yasda had a history of Seizure disorders three to four every day for the past several years. Initially her parents treated her for the seizure in Bareilly and Neeraj Clinic in Haridwar for three years and her parents' recall that about 1.5 lakh has been spent on her treatment in these clinics. She was treated in RML Hospital, and some antiepileptic drug re- 
acted and her situation turned very worse. Her parents became hopeless of the treatment of these seizures in hospitals of Delhi -RML hospital, GB Pant hospital etc.

She started her treatment again in our hospital and frequency reduced to one or nil per day as tells her husband. Because of the treatment she stays with her husband and two children with her parents in Nand Nagari. Her husband works in private factory earn very merge amount salary and is very difficult to support her treatment in private clinical setting. Her husband mentioned that he stay with his in-laws house in order to cares her and our children.

8) Sumi, 25 years married woman who resides with her parents in Radha Vihar, Saboli extension, Delhi. She had been married in the Meerut. She had developed the complained of seizure just after her $3^{\text {rd }}$ child. Prior to this she developed inability to pronounce the words and failed to express herself and gradually she lost the recognition to all the family members. Her husband who resides in Meerut left her with three children in her parents' house in Delhi where she is living as deserted woman for five years and taking different treatment. Initially she took treatment from the molvie and bhagat in Delhi, Meerut and Gaziabad and no cure for the disease and none of these healers told her about her disease. They were treating her for the supernatural causation: her parents' thinks it is upri hawa, heavenly punishment, as she had experiences of the disturbed her speech dysfunction, could not recognized proper words and failing to recognized the family members. Her parents stay in Delhi and she had been married for years and had three children staying with her as her husband left her because of the disease. She visited LNJP Hospital (formerly Irwin hospital) where she took treatment for the seizure but did not get the cure. But a local molvee, a local Muslim healer told her about this disease and directed them to hospital which is very near to her house. She visited the hospital with her brother. Sumi had a diagnosed as General Tonic clonic Seizures (GTCS) and her treatment had been started for one and half years. Since then the treatment has been very effective and seizure frequency has reduced much. Earlier seizures used to be for an hour or more but after the treatment at least it is reduced for 5 to 10 minute. In marital family life her husband left her due to seizure and her husband does not care her and her children. Her parental family members are supporting her and her children too. Her brothers are looking after the treatment part from the hospital. It is told that her brother took loans and claimed expenditure of Rs 25,000/for her treatment till now. Sumi is second among four children, two brother and two sisters. She had one elder sister who is married and has normal children, then a brother who is married and has normal children and then Sumi, a $3^{\text {rd }}$ child of her parents followed by a married brother with normal children. Sumi has one elder son and two daughters. She is being cared by her two brothers in most of the time and her father also cares her. Sumi is taking care of her children during the day but during nights she develops the seizures in night while in sleep.

\section{Epileptic Married Man and His Mental Agony?}

9) $K A, 30$ years, married and living in the Kastalakasambad, Railway station, Ghaziabad. He had been blessed six children but now two children, one boy and a girl, alive and is living with his wife in the same vicinity where his other five married brothers are living. KA being the eldest in the family and earlier he used to support the family. But after the seizure disorder he lost his job and failed to support economically his family. Prior to this he used to work in the grill-gate, Iron Gate welder in the local shop and used to earn good amount to support his family and brothers too. But after the diagnosis of this problem, he is under the treatment from our hospital and his neighbor comments on his behavior as the pagal (mad). His intimate relationship with his wife has become stressful. His wife presses him to stay separate from his other brothers. But $K A$ refuses to his wife as he thinks that during the seizure who will help him? He stressfully mentioned me that because of the disease I will remain here together. He expresses his suffering as

"mujhe lagta he ke mai mar jaunga, mere family members mere dek-bhal nahi karte lekin mai bahar bhi rah sata hu par mujhe es rog ke karan yaha rahna padta he, kyuki parivaar ke log mere dek bhal karege yadi mai yaha rahta hu to"(I feel that I will die because my family members do not care me. I can stay outside this house but I have to live here so that they will definitely care me, therefore I do not leave or separate from my parents)

\section{He further felt that}

Ye bimari mujhe buri lagti he na jane kab keya ho jaye? Mai kya karu? (This disease I do not like much, it not clear when can and what can happen? What should I do now?)

Says that his old parents support him at the time of seizure and $K A$ need more care during this time. His wife supports the old parents in laws in the care of her husband. But other of his brothers and their wives do not support them in the care. Further his younger brothers curse him as he is not contributing economically. $K A$ took the traditional treatment from the local healers in different places with his parents. He further also adds about the places where he had been treated for the seizure. He went to Meerut with his parents to traditional healer who told his parents "kuch kara rakha he apke ghar me!" (Some body has done something to your house). This and many other healer gave him several tabeej (amulets) to tie on upper arm, but it did not cured the disease, as felt $K A$. Then he also went to Gondi sarai, a village near Hapur in Gaziabad where he is receiving the treatment while getting the treatment in the tertiary care hospital. Moreover his parents have already planned a visit to dargah (Muslim religious shrin)/manjaar in Roorkee and Naurangabad for the treatment. However $K A$ is well aware about this hospital treatment and admits the benefits-reduced the frequency seizures now to once in two to three months which was earlier reveres-two or three episodes in one month. Parents still have faith that religious cure from the manjaar in Roorkee and Naurangabad, UP will fully cure the seizure of their son.

\section{Family and Kinship Care: Patients with Dementia}

On gazing the detail of family, sibs and other possible care givers in the family and kinship system, it seems from these brief, wherein we have restricted use of the family detail. They have possible resources are available for care and treatment of dementia and epilepsy. In case of dementia the clinical symptoms appear when a person cross the age of 50 years or above, in our analysis the average age is 63.5 years (Table 1), here at this age nobody is around the grand old person as patient, man or woman, with dementia expect the spouse-husband or wife. 
The children by this time get married off and stay away or separated from their parents. The poor persons with dementia remain behind and don't know with whom she or he is living with. They, as caring affinal kin knows well what he or she is to us but the person with dementia is now in a different personhood in the family.

In our analysis we observed that among patients with dementia remains with their spouse-either husband or wife. Only unmarried children, daughters or sons remain to support in the family. Most of the children married, particularly son and their wife either prefer to stay away from the parental house or even staying together then they remains functionally away from the care giving mechanism though structurally together with their families. Wives and the children are living in the different space within the same parental house. Such are the sons who are forced to stay with as they cannot go outside to live. Like in case of HKD have seven married children, four sons and three daughters. Daughters are away and outside the kinship care network as they remain with the in laws. Her sons hardly find time for the care their mother and whole responsibility remains with father, who is entirely for her care besides other home chore.

In contrast, $\mathrm{KR}$, another woman from the rural area of Baruat near Delhi and her husband refused to care her. She also denied care by her elder married son separated from the parental family and starts living separately with his wife and children and do not care to his mother. Remaining unmarried sons, under the stress of care, approach the elder married sister in Delhi for help in her treatment, as dutiful daughter she took all responsibility for her mother treatment. However the unmarried younger brothers economically support her elder sisters in her treatment. Married daughter and her husband are taking care of KRhere, it reminds us about a film "complaints of a dutiful daughter" by Deborah Hoffman and the Taylor's article "on recognition, caring and Dementia" and the Politics of care, a commentary of Lawrence Cohen on the latter article. In this film a tag appears "What's, a daughter to do when her mother ask: “how exactly are we related?” (c.f. Cohen, 2008).

Similarly, parents, either father or mother left behind uncared by their sons in their home setting. Their sons are doing the job in far off cities, as in case BS, father, left behind to mother alone for care in their village. Their sons working in Delhi and upon knowing the situation of the father they brought him in Delhi for his treatment as one (RS) of us was interviewing the son as well as his father being treated for dementia in the inward patients. It is planned after the discharge of BS would be sent back to his village in a district of eastern Uttar Pradesh, India where his wife will look after again. However other lateral kinsmen-brothers of BS and their wives and children will remain functionally away for the care their elder brother. In contrast, $\mathrm{AD}$, a woman of 75 years being treated for dementia, who is cared well not only by her sons but by their wives too and her grand children also care the grandmother. The care of elderly person with dementia pose a different stress to the care givers-usually the spouse either husband or wife-least supported by the eldest married sons, however younger unmarried sons always extend their help. The family and kinship caring of dementia is different in many respect to epilepsy.

Similar observation, as our analysis of patients with dementia in the families of the northern part of India has revealed, Hargave (2006) reported the family and kinship caring ties of among African-American caregivers to the person with dementia. She emphasized on the features of family and kinship in
African-American caregivers for dementia patients mentioned that the nature of the relationship between the dependent elder and his/her caregiver vary across ethnic group. White caregivers are mostly are the spouses, whereas African-American caregivers are more likely to be adult children, extended relatives, or friends (Ibid). Several studies emphasizing the care giving aspects among the African-American are well reported in caring the people with dementia among black and white people-a comparison of adaption, adjustment, and service utilization for the Care of dementia in Black and white caregivers (Hinrichsen \& Ramirez,1992), different issues of race, ethnicity, and culture in care giving research (Dilworth-Anderson, Williams, \& Gibson, 2002), dynamics of care giving of demented elder among black and white families (Lawton et al., 1992), and an analyticcal review of racial, ethnic, and cultural differences in dementia care givers (Connell \& Gibson, 1997).

In general, African-American caregivers as compared to white caregivers are more likely to be younger, unmarried, with less formal education, and fewer financial resources. Because of their lower income and higher poverty rates, the financial stress of care giving may pose a greater emotional burden on African-American caregivers (Hargrave, 2006). She elaborately mentioned in detail that African-American caregivers, as compared to white caregivers, are more likely to provide more hours of care, higher-intensity care, and are more likely to report more unmet needs in terms of support and access to services (ibid). Many African-American caregivers are also actively caring for other people in addition to the frail elderly, such as minor children, grandchildren, and other family members. Even though African-American caregivers are caring for severely debilitated elders and other family members, they are less likely than white caregivers to use formal care services like nursing homes (Haely et al., 1996).

Numerous studies have reported that African-American family care giving of dependent elderly persons is performed within a collectivistic structure composed of different people with varying levels of involvement in daily care giving activities (Dilworth-Anderson, Williams, Cooper, 1995; Burton, Dilworth-Anderson et al, 1999). Since kinship ties are a very powerful force in African-American families, many investigators thought that African-American caregivers receive significant support from their network of family members. However, more recent studies suggest that prior research may have overestimated the availability and extent of support that African-American caregivers receive from other family members (Hinrichsen \& Ramirez, 1992; Cox \& Monk, 1996; Fox, Hinton, \& Levkoff, 1999). These studies suggest that adult children of dependent elderly persons may be adversely affected by the other commitments in their own lives, which may severely limit the amount of assistance they can offer frail African-American elderly. In the midst of an extended family network, one primary caregiver emerges who bears the burden of being the sole decision maker, and has few opportunities for shared responsibility and shared decision making (Fox, Hinton, \& Levkoff, 1999).

\section{Family and Kinship Care: Patients with Epilepsy}

Let us see the how do patients with epilepsy-children with epilepsy, married women and married men deal with disease and experience living with epilepsy. We already summarize the coping strategies of these groups elsewhere (Singh et al., 2009a, 2009b) followed by the latter analysis. 
There is much variability in content analysis of interviews. Some major themes were evident from the data. Attitudes to epilepsy were in some cases dominated by a marked non-acceptance, where in other cases the diagnosis appeared to be a fairly well-integrated part of life. In most of the cases patients elaborately described their experiences of the epilepsy. They feel as the epilepsy is disease of uncertainty and disappointment. After having a seizure were clearly expressed, one of the patients said that he always believed the most recent seizure to be the last and he experienced an enormous disappointment and sadness after each new seizure. Medical treatment makes these patients more curious about the medicine- how long these will continue. There were expressions of a negative self-image and even of self-destructive tendencies, as we had seen in case of Ush and two sisters Arth and Svit whose mother expresses a state of hopelessness from the disease. There are similar expressions in many other cases. The feeling of insecurity was often present. Perceptions of the reactions of other people to epilepsy emerged as another problem-stigma. Several interviewees demonstrated some difficulties dealing with the reactions of other people: what other people say or think about their disease. Almost all declared that they had sometimes met a negative attitude or lack of understanding from other people.

A number of school children with epilepsy had the experience of being harassed at school because of epilepsy, which they had a strong negative impact on their lives. When discussing their employment situation and leisure time activities, the attitudes of others often emerged as the greatest problem. Some individuals felt restricted at work because they couldn't take part in certain tasks, due to the risks involved or because they did not have a driving license. There were also a number of cases who were excluded from employment because of the disease, in case of $K A$, a married man lost his job and added as burden to parental family.

Cognitive problems were reported, as in case of $K V$ we found this school boy not only suffered from the seizures disorders but also facing the caste discrimination-peculiar to Indian subcontinent-in the class from his classmates as well as from the teachers who forced him to discontinue his studies. Similarly SNZ, a Muslim girl from lower socio economic group also faced the social discrimination in the class due to disease. School going children with epilepsy mostly complain concerned to their memory, but a few experienced speech or attention difficulties. Feelings of fatigue or of being easily exhausted were also frequently noticed.

Married Women often pose different problems. As we have seen in case of Yasda who is being accompanied by her husband, who stay in house of his father-in-law for better care her and as their house is near to hospital. Her husband does some work in private factory and hardly meet his personal family expenditure. Similarly case of Svit, an elder sister of Arth who is married and on the treatment from the hospital and periodically visit our hospital with her mother often accompany both sisters. These aspects give a deeper insight about how the problem is being experienced among the family members of such patients.

Family and kinship care analysis of school children with epilepsy reveals that parents are caring their children, besides maternal and paternal uncle, as in case of $V K$ and $K V$. Whereas school going girls remains under the supervision their mothers and visit hospital for the treatment with them. They take decision about treatment of their children, boys or girls, where to go for the treatment. Parents are around them most of their time rarely other kinsmen care for long. Married women, Arti and Svit, remains with their mother, they frequently visit hospital together rather than with their husband or their affinal kins. Their husband and his other family members are not involved in their care or treatment and remain uninformed. Perhaps it is due to the stigma associated to the disease. In contrast, Yasda, another married woman being cared by her husband and stay near to house of in-laws who are staying very near to this hospital in Delhi. Her husband cares his wife and his children. He presented her along with his father-in-law in OPD. Still another aspect of the husband as care givers we observe that one husband has left his wife, Sumi and her three children back to the parents of his wife in Delhi where her younger brothers and parents care. They manage her treatment and her children too. It is this aspect which becomes the burden to the parental family of the women with epilepsy. Patients are living with epilepsy or they have learned to live with such diseases. Married epileptic man still looks for parental support bedsides his wife and his children. These are the uninvited suffering added to one who is living together just because of being affinal kins or sibs but this burden of care being carried along in the life. Though they are no more Patients, but they have transformed as People living with epilepsy!

In brief the children with epilepsy are in direct supervision of the parents and occasionally close relatives support. Married women present differently-presenting their husband as caring, not caring or even not aware of the diseases of their wife suffering as patient with epilepsy. They remain voiceless or unheard!

\section{Conclusion}

The behavioral and psychological symptoms of dementia and epilepsy are major causes of stress to family and kinsmen providing care to patients with epilepsy and dementia. Above interpretation from the family and kinship care analysis, we are being constraint to think, that does family and kinship caring still central of such patients? But the caring in the dementia varies from the epilepsy in family situation. In case of former, old people suffer only whereas in epilepsy anybody can suffer at any age or any available kinsmen can care the epileptic person but in case of dementia it is, in most of cases, only the spouse cares. Since the family and kinship care is still central of caring such patients. Then training, sensitization or orientation programme should be designed for family and kinship caregivers in the management of these diseases, including problem solving, memory training, and reality orientation. These can reduce the level of agitation and anxiety in patients with dementia. The challenge for developing countries like ours is to develop culturally appropriate interventions that can be delivered, within existing resources, as support to the role as caregivers in their families.

We feel about a care giving model for the north Indian population groups which should be home based care coupled with regular training about the modalities of caring must be given to the family and kinship members of the patients of dementia and epilepsy (2). Their care giver should be provided material and other relevant information about such diseases. In many developing countries, people with dementia are still thinking it as the madness and consult the traditional healers and such consultations are more common in patients with epilepsy as we have 
seen in our cases studies. A simple model for the management of dementia, epilepsy and other neurological disorders must be based on existing community-based health care resource providers, trained to provide such services which may reduce burden of caregivers in the family of such diseases.

\section{Acknowledgements}

We are thankful to Dr. Suman S. Khuswaha, Associate Professor of Neurology, in whose OPD one of us (RS) worked and whose useful discussions on the relevance of community based studies and regular training to the families of care givers. We also thank Dr. Anthony Aldrein, then senior DNB Candidate, now Assistant Professor (Neurology), Dr. Sushma Kumari, Ravi Kishen Jha, Himanshu K Singh, Psychiatric Social workers, for their valuable discussion on various issues of patients with dementia and epilepsy. We extend our gratitude to Professor (Dr.) Meena Gupta, former Director, IHBAS and Professor of Neurology, GB Pant hospital, Delhi for her encouragement.

\section{Note}

This is the revised Paper of Dementia and Epilepsy: Family and Kinship care Analysis which presented in the Panel on "Medical Pluralism, Sectors of Health Care and Health Seeking Behavior: Problems and perspective in the Critical Medical Anthropology", $16^{\text {th }}$ World Congress of International Union of Anthropological and Ethnological Sciences (IUAES 2009) held from $27^{\text {th }}$ to $31^{\text {st }}$ July 2009, Kunming, Yunnan, China.

1) A paper "People living with Epilepsy: Narrative of OPD patients.” By Ravinder Singh, Kiran Bala, R. K. Jha and Sushma Kumari, presented in the Panel on Public Health and Anthropology, of the $16^{\text {th }}$ World Congress of The International Union of Anthropological and Ethnological Sciences (IUAES 2009) $27^{\text {th }}$ to $31^{\text {st }}$ July 2009 in Kunming, Yunnan, China has included these cases studies which one of us (RS) had done during the home visits.

2) We run an epilepsy clinic in the afternoon for the group meeting wherein old patients of epilepsy and their care givers usually meet with the care givers of new cases of epilepsy in their family. Our psychiatric social work colleagues Ravi K. Jha, Sushama Kumari and Himanshu Kumar Singh facilitate the meeting and often one of us (RS) attends such meeting as the non-participant observer. Here both families exchange their experiences of caring epilepsy patients in their family situation for their kinsmen and after sometimes they become friends and among themselves they find solution of their day to day problems. We encourage the caregivers to participate in support groups and to reduce caregiver burden and to learn new effective coping strategies during these meetings. This is an empowering approach to the people living with epilepsy.

\section{REFERENCES}

Burton, L. M., \& Dilworth-Anderson, P. (1999). The intergenerational family roles of aged black Americans. Marriage and Family Review, 16, 311-322.

Brodaty, H., \& Gresham, M. (1989). Effect of a training programme to reduce stress in cares of patients with dementia. British Medical Journal, 299, 1375-1379. doi:10.1136/bmj.299.6712.1375

Borneman, J. (1997). Caring and being cared for: Displacing the marriage, kinship, gender and sexuality. International Social Sciences
Journal, 154, 573-584.

Chandra, V., Ganguli, M., Pandav, R., Johnston, J., Belle, S., \& DeKosky, S. T. (1998). Prevalence of Alzheimer's disease and other dementias in rural India: The Indo-US study. Neurology, 51, 1000 1008. doi:10.1212/WNL.51.4.1000

Chandra, V., Pandav, R., Laxminarayan, R., Tanner, C., Manyam, B., Rajkumar, S., Silberberg, D., Brayne, C., Chow, J., Herman, S., Hourihan, F., Kasner, S., Morillo, L., Ogunniyi, A., Theodore, W., \& Zhang, Z. (2006). Neurological disorders, chapter-32 in mental health disorders. Geneva: DCPP, WHO, The International Bank for Reconstruction and Development/the World Bank.

Cohen, L. (1994). Old age: Cultural and critical perspectives. Annual Review of Anthropology, 23, 137-158. doi:10.1146/annurev.an.23.100194.001033

Cohen, L. (1998). No aging in India: Alzhiemer's, the bad family, and other modern things. Berkeley, CA: Berkeley University of California Press. doi:10.1525/california/9780520083967.001.0001

Cohen, L. (2003). Is treating dementia ironic? In M. Lambek, \& P. Anzte (Eds.), Illness and irony: On the ambiguity of suffering in culture (pp. 122-134). New York: Berghahn.

Cohen, L. (2008). Politics of care: Commentary on Janelle S. Taylor's “on recognition caring, and dementia”. Medical Anthropology Quarterly, 22, 336-339.

Connell, C. M., \& Gibson, G. D. (1997). Racial, ethnic, and cultural differences in dementia care giving: Review and analysis. Gerontologist, 37, 355-364. doi:10.1093/geront/37.3.355

Cox, C., \& Monk, A. (1996). Strain among caregivers: Comparing the experiences of African American and Hispanic caregivers of Alzheimer's relatives. International Journal of Aging and Human Development, 43, 93-105. doi:10.2190/DYQ1-TPRP-VHTC-38VU

Dilworth-Anderson, P., Williams, S. W., \& Cooper, T. (1999). Family care giving to elderly African Americans: Caregiver types and structures. The Journals of Gerontology: Series B, 54, S237-S241. doi:10.1093/geronb/54B.4.S237

Dilworth-Anderson, P., Williams, I. C., \& Gibson, B. E. (2002). Issues of race, ethnicity, and culture in care giving research: A 20-year review (1980-2000). Gerontologist, 42, 237-272. doi:10.1093/geront/42.2.237

Fox, K., Hinton, W., \& Levkoff, S. (1999). Take up the caregiver's burden: Stories of the care for urban African American elders with dementia. Culture, Medicine and Psychiatry, 23, 501-529. doi:10.1023/A:1005520105518

Gourie-Devi, M., Gururaj, G., Satishchandra, P., \& Subbhakrishna, D. K. (2004a). Prevalence of neurological disorders in Bangalore, India: A community-based study with a comparison between urban and rural area. Neuroepidemiology, 23, 261-268. doi:10.1159/000080090

Gourie-Devi, M., Gururaj, G. and Satishchandra, P. (2004b). Delivery of epilepsy care to the community: Towards the national epilepsy control programme. In S. P. Aggarwal (Ed.), Mental health-An Indian perspective (1946-2003) (pp. 295-305), New Delhi: DGHS, Ministry of $\mathrm{H} \& \mathrm{FW}$.

Graham, J. E. (2006). Diagnosing dementia: Epidemiological and clinical data as cultural text, Chapter-4. In A. Leibing, \& L. Cohn (Eds.), Thinking about dementia-culture, loss, and the anthropology of senility (pp. 80-105). New Brunswick, NJ: Rutgers Universe Press.

Haley, W. E., Roth, D. L., Coleton, M. I. et al. (1996). Appraisal, coping, and social support as mediators of well-being in black and white family caregivers of patients with Alzheimer's disease. Journal of Consulting and Clinical Psychology, 64, 121-129. doi:10.1037/0022-006X.64.1.121

Hargrave, R. (2006). Caregivers of African-American elderly with dementia: A review and analysis. Annals of Long-Term Care, 14, 398403

Haupt, M., Karger, A., \& Janner, M. (2000). Improvement of agitation and anxiety in demented patients after psycho educative group intervention with their caregivers. International Journal of Geriatric Psychiatry, 15, 1125-1129. doi:10.1002/1099-1166(200012)15:12<1125::AID-GPS257>3.0.CO; 2-F

Henderson, A. S., \& Jorm, A. F. (2000). Definition of epidemiology of dementia: A review. In M. Mario, \& N. Sartorius (Eds.), Dementia 
(pp. 1-34). West Sussex: John Wiley. doi:10.1002/0470842350.ch1

Hendrie, H. C., Osuntokun, B. O., Hall, K. S., Ogunniyi, A. O., Hui, S. L., Unverzagt, F. W. et al. (1995). Prevalence of Alzheimer's disease and dementia in two communities: Nigerian Africans and African Americans. American Journal of Psychiatry, 152, 1485-1492.

Hinrichsen, G. A., \& Ramirez, M. (1992). Black and white caregivers: A comparison of their adaption, adjustment, and service utilization. Gerontologist, 32, 279-381. doi:10.1093/geront/32.3.375

Hinton, L., Flores, Y., Franz, C., Hernadez, I., \& Mitteeness, L. S. (2006). The borderlands of primary care: Physician and family perspective on "troublesome" behavior of people with dementia. Chapter 2. In A. Leibing, \& L. Cohn (Eds.), Thinking about DementiaCulture, Loss, and the Anthropology of Senility (pp. 43-63). New Brunswick, NJ: Rutgers Universe Press.

Jorm, A. F., \& Jolley, D. (1998). The incidence of dementia: A metaanalysis. Neurology, 51, 728-733. doi:10.1212/WNL.51.3.728

Kauman, S. R. (2006). Dementia-near-death and "life itself”. Chapter 1. In A. Leibing, \& L. Cohn (Eds.) Thinking about dementia-culture, loss, and the anthropology of senility (pp. 23-42). New Brunswick, NJ: Rutgers Universe Press.

Khurana, S., Bala, K., Singh, R., \& Shrama, V. (2012). Childhood epilepsy: Knowledge, attitude and perception of the school teachers of Delhi. Abstract. In 56th Annual Conference of Indian Public Health Association (IPHA) for Public Health Priorities for the 12th Plan (p. 28). Kochi, 10-12 February 2012, Abstract No. 486.

Kleinman, A. (1995). The social course of epilepsy: Chronic illness as social experience in interior China, Chapter-7. In Writing at the margin-discourse between anthropology and medicine. Berkeley, CA: University of California Press.

Leibing, A., \& Cohn, L. (2006). Thinking about dementia-culture, loss, and the anthropology of senility. New Brunswick, NJ: Rutgers Universe Press.

Lawton, M. P., Rajagopal, D., Brody, E., Kleban, M. H. (1992). The dynamics of caregiving for a demented elder among black and white families. The Journals of Gerontology, 42, S156-S164. doi:10.1093/geronj/47.4.S156

Lock, M., Llyod, S., \& Prest, J. (2006). Genetic susceptibility and Alzheimer's diseases. Chapter-6. In A. Leibing, \& L. Cohn (Eds.), Thinking about Dementia-Culture, Loss, and the Anthropology of Senility (pp. 123-154). New Brunswick, NJ: Rutgers Universe Press.

Marriott, A., Donaldson, C., Tarrier, N., \& Burns, A. (2000). Effectiveness of cognitive-behavioural family intervention in reducing the burden of care in carers of patients with Alzheimer's disease. British Journal of Psychiatry, 176, 557-562. doi:10.1192/bjp.176.6.557
Rajkumar, S., Kumar, S., \& Thara, R. (1997). Prevalence of dementia in a rural setting: A report from India. International Journal of Geriatric Psychiatry, 12, 702-727. doi:10.1002/(SICI)1099-1166(199707)12:7<702::AID-GPS489>3.0. $\mathrm{CO} ; 2-\mathrm{H}$

Saillant, F., \& Genset, S. (2007). Medical anthropology—Regional perspective and shared concerned (p. 27). USA: Blackwell Publishing.

Sharma, V., Singh, R., Talwar, U. K., \& Bhargava, R. (2011). Ethical and legal issues related to dementia and epilepsy, Chapter-25. In V. Sharma, \& S. Malhotra (Eds.), Clinical neuropsychology assessment and rehabilitation: A practical approach (pp. 363-376). Agra, UP: Harprasad Institute of Behavioral Sciences.

Singh, R., Bala, K., Jha, R. K., \& Kumari, S. (2009a). Dementia and epilepsy: Family and kinship care analysis. Unpublished paper submitted to Panel on "medical pluralism, sectors of health care and health seeking behavior: Problems and prospective in the critical medical anthropology". 16th world congress of International Union of Anthropological and Ethnological Sciences (IUAES 2009). Kunming, 27-31 July 2009, Yunnan.

Singh, R., Bala, K., Jha, R. K., \& Talwar, U. K. (2009b). People living with epilepsy-narratives of OPD patients. Unpublished paper submitted to Panel on Public Health and Anthropology, 16th World Congress of The International Union of Anthropological and Ethnological Sciences (IUAES 2008). Kunming, 27-31 July 2009.

Singh, R., Khurana, S., Bala, K., \& Bhargava, V. (2011). Social, cultural and ethical issues in dementia, chapter-24. In V. Sharma, \& S. Malhotra (Eds.), Clinical neuropsychology assessment and rehabilitation: A practical approach (pp. 352-362). Agra, UP: Harprasad Institute of Behavioral Sciences.

Singh, N., Sharma, V., \& Singh, R. (2012a). Spiritual psychotherapy of caregivers of patients with epilepsy: An Indian perspective for care givers. Abstract. International Conference on Recent Advances in Cognition and Health (pp. 40-41). 23-24 January 2012, Varansai: Department of Psychology, SAP (DRS1), BHU.

Singh, N., Sharma, V., \& Singh, R. (2012b). Care giver burden, personality characteristics and coping strategies of Care givers of patients with epilepsy. Abstract. International Conference on Recent Advances in Cognition and Health (pp. 40-41). 23-24 January 2012, Varansai: Department of Psychology, SAP (DRS1), BHU.

Taylor, J. S. (2008). On recognition, caring, and dementia. Medical Anthropology Quarterly, 40, 313-335. 